\title{
Micronutrient deficiencies after RYGB surgery
}

Deficiencies in micronutrients such as copper and zinc might be common in patients who undergo Roux-en-Y gastric bypass (RYGB) surgery, suggest two new studies.

During RYGB surgery, a large part of the stomach and duodenum is bypassed, and uptake of micronutrients that are typically absorbed in these regions is diminished. Several studies have focused on the micronutritional deficiencies of patients who had RYGB surgery, in particular iron deficiency. Data documenting copper and zinc deficiency are less abundant.

Nana Gletsu-Miller and colleagues investigated the prevalence of copper deficiency in a population of 136 patients who underwent RYGB surgery at the Emory Bariatric Center (Atlanta, USA). The researchers analyzed medical evaluation and nutritional screening data collected between March 2007 and March 2009. The prevalence of copper deficiency after surgery (defined as $<11 \mu \mathrm{mol} / \mathrm{l}$ in men and $<12.6 \mu \mathrm{mol} / 1$ in women) was $9.6 \%$, which is in line with previous findings from smaller studies. Copper deficiency was equally prevalent in patients within the first year, within years 1-3 or within years 3-5 after surgery.

Gletsu-Miller et al. also sought to determine the incidence of copper deficiency associated with RYGB surgery by analyzing 16 female patients with BMI $\geq 35 \mathrm{~kg} / \mathrm{m}^{2}$ before and after surgery. The researchers observed that plasma copper concentrations 6 and 24 months after surgery decreased from those at baseline (by $10.8 \%, P=0.03$, and by $10.1 \%, P=0.04$,

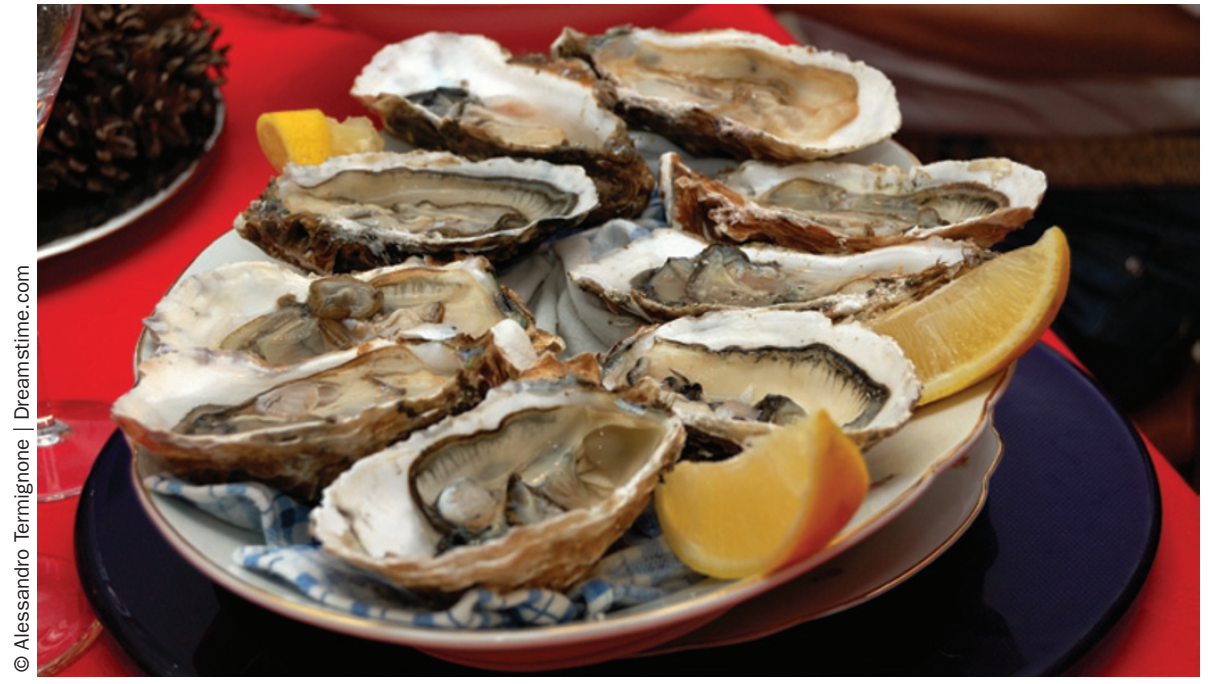

respectively). The calculated incidence of copper deficiency following RYGB was $18.8 \%$. Copper deficiency can have serious clinical effects, such as anemia and neuropathy. "We want patients and doctors to be aware of the risk of copper deficiency so that patients receive proper monitoring and treatment," concludes Gletsu-Miller.

Manuel Ruz and co-workers assessed zinc status and zinc absorption before and at 6,12 and 18 months after RYGB surgery in a population of 67 women with $\mathrm{BMI} \geq 40 \mathrm{~kg} / \mathrm{m}^{2}$ or $\mathrm{BMI} \geq 35 \mathrm{~kg} / \mathrm{m}^{2}$ and co-morbidity who were treated at the University of Chile Clinical Hospital. The results of three of the five approaches used to assess zinc status showed a significant decrease in zinc concentration 12 or 18 months after RYGB surgery. This result contrasts with the findings by Gletsu-Miller et al., who did not see changes in the plasma zinc concentration in their population.

Ruz et al. also observed that the percentage of zinc absorption was significantly reduced after RYGB surgery, from $32.3 \%$ at baseline to $13.6 \%$ at 6 months and $21.0 \%$ at 18 months. Ruz hopes that the availability of data on the magnitude of zinc absorption impairment after RYGB surgery will allow for a better estimation of replacement therapy with supplemental zinc.

\section{Joana Osório}

Original articles Gletsu-Miller, N. et al. Incidence and
prevalence of copper deficiency following roux-en-y
gastric bypass surgery. Int. J. Obes. (Lond.) doi:10.1038/
ijo.2011.159 | Ruz, M. et al. Zinc absorption and zinc
status are reduced after Roux-en-Y gastric bypass: a
randomized study using 2 supplements. Am. J. Clin. Nutr.
doi:10.3945/ajcn.111.018143

